\title{
Effect of Flux Cored arc Welding Process Parameters on Corrosion Resistance of Austenitic Stainless Steel Claddings
}

\author{
Marlon Muniz Nunes * * (), José Henrique de Freitas Gomes ${ }^{b}$, Tarcisio Gonçalves Brito ${ }^{a}$,
}

\author{
Reny Angela Renzettia (1)
}

${ }^{a}$ Universidade Federal de Itajubá, Itabira, $M G$, Brasil

${ }^{b}$ Universidade Federal de Itajubá, Itajubá, MG, Brasil.

Received: July 30, 2019; Accepted: October 30, 2020

\begin{abstract}
Cladding process can be used to create corrosion resistant surfaces from low cost materials. Austenitic stainless steel has been extensively used for weld cladding. It has excellent corrosion resistance and good weldability. In this context, experiments were conducted by depositing AWS E316LT1-1/4 stainless steel on to AISI 1020 carbon steel and the effects of flux cored arc welding (FCAW) process parameters on pitting and intergranular corrosion was investigated. Response surface methodology (RSM) based central composite design (CDD) was used to predict and develop the mathematical models for process parameters on corrosion resistance. The responses of interest were obtained by double loop electrochemical potentiokinetic reactivation (DLEPR) and potentiodynamic polarization tests. The process parameters analyzed were the wire feed rate, welding voltage, welding speed and nozzle to plate distance. All RSM models developed were statistically significant and presented good adjustments. The results indicated that the process parameters are important in determining the degree of sensitization and pitting potential, and the interaction between parameters cannot be neglected.
\end{abstract}

Keywords: Cladding, 316L stainless steel, corrosion, flux cored arc welding, response surface methodology.

\section{Introduction}

Low carbon steels are extensively used in the offshore oil and gas industry due to their good mechanical properties and low production $\operatorname{cost}^{1,2}$. However, the low corrosion resistance of carbon steel causes losses to the world economy. It is estimated that the cost of corrosion problems has been about 2.2 trillion USD worldwide in $2016^{3}$. In this way, extending the useful life of the industrial components can result in significant savings, reducing maintenance and replacement of parts. The cladding process can be used for such purposes. The application of stainless steel cladding by welding process aims to obtain corrosion resistant surfaces from common materials and low $\operatorname{cost}^{4-8}$, such as low carbon steels.

Austenitic stainless steels have excellent corrosion resistance and good weldability ${ }^{9,10}$ for these reasons they are commonly used as a cladding metal. However, the mixing of elements presents in the carbon steel with the stainless steel elements can causes metallurgical problems and reduce the corrosion resistance ${ }^{5,6,11}$. For example, the increase in carbon concentration in the austenitic stainless steel cladding leads to the precipitation of chromium carbides, which increase the susceptibility to intergranular corrosion. In addition, the microstructure of austenitic stainless steel generally shows a $\delta$-ferrite phase after cladding ${ }^{12}$. This phase is the results from the segregation of alloying elements, mainly $\mathrm{Cr}$, during solidification ${ }^{13,14}$. Thus, the higher the fraction of $\delta$-ferrite the lower the pitting corrosion resistance ${ }^{15}$.

*e-mail: marlon.emt2010@yahoo.com.br
In this context, it is necessary to study and control the welding parameters to achieve a high-quality cladding. Various processes can be used for cladding operations, such as submerged arc welding (SAW), gas tungsten arc welding (GTAW), flux-cored arc welding (FCAW) ${ }^{16}$, plasma arc welding (PAW), gas metal arc welding (GMAW), electroslag welding (ESW) and explosive welding ${ }^{7,17}$. The FCAW process presents some advantages such as high productivity and capacity to automation ${ }^{4,18}$.

Several researchers studied the effects of FCAW parameters on bead geometry, dilution and ferrite fraction. Palani and Murugan ${ }^{19}$ investigated the effect of flux cored arc welding process parameters on ferrite content of AISI $317 \mathrm{~L}$ austenitic stainless steel claddings using response surface methodology. Balan et al. ${ }^{20}$ studied the effect of process parameters on bead geometry during flux cored arc welding using Taguchi method. Senthilkumar and Kannan ${ }^{21}$ investigated the effect of flux cored arc welding process parameters on bead geometry in super duplex stainless steel claddings using response surface methodology. Senthilkumar et al. ${ }^{7}$ carried out the optimization of flux cored arc welding process using Taguchi and genetic algorithm. The authors studied the effects of process parameters on bead width, reinforcement height. Gomes et al. ${ }^{8}$ investigated how the flux-cored arc welding (FCAW) parameters influence geometry, productivity, and the surface quality of the stainless steel claddings using response surface methodology. Palani and Murugan ${ }^{4}$ carried out the optimization of weld bead geometry for stainless steel claddings deposited by FCAW using response surface methodology. 
However, only few studies have reported correlations between welding parameters and corrosion of austenitic stainless steels cladding. Balan et al..$^{22}$ carried out the optimization of flux cored arc welding process using response surface methodology and simulated annealing algorithm. The authors studied the effects of process parameters on dilution, penetration, bead width, reinforcement and ferrite number and performed potentiodynamic polarization test on optimized cladding. Murugan and Kannan ${ }^{23}$ studied the effects of flux cored arc welding parameters on pitting corrosion resistance of duplex stainless steel clad metals. They concluded that pitting potential increased with increasing welding current and tip to workpiece distance and decreased with increasing welding speed and welding angle. Palani and Murugan ${ }^{14}$ investigated the effect of FCAW parameters (welding speed, welding current and nozzle to plate distance) on pitting corrosion resistance of AISI 317L stainless steel claddings. They concluded that the pitting potential was more sensitive to changes in welding speed than the other two parameters.

It is worth noting that no literature which correlates the effects of FCAW parameters on degree of sensitization was found. Besides that, the above literatures show that the response surface methodology was used by various researchers for developing mathematical model and analyzing the process parameters. For these reasons, the present paper investigated the effects of flux cored arc welding process parameters on pitting and intergranular corrosion resistance in $316 \mathrm{~L}$ stainless steel cladding using response surface methodology (RSM).

\section{Experimental Method}

Response surface methodology was used for the planning the experiments, collecting the data, modeling the responses of interest (pitting potential and degree of sensitization) and parameters effects analysis. RSM is defined by Montgomery ${ }^{24}$ as a collection of mathematical and statistical techniques that are useful for modeling and analysis in applications where a response of interest is influenced by several variables and the objective is to optimize this response.

\subsection{Experiment planning}

The design matrix was based on a central composite design (CCD), created for four parameters at two levels $\left(2^{K}=2^{4}=16\right)$, eight axial points $(2 k=8)$, and seven center points. This resulted in 31 experiments. The process parameters analyzed were the wire feed rate $(W)$, welding voltage $(V)$, welding speed $(S)$ and nozzle to plate distance $(N)$, as shown in Table 1. In the CCD matrix, a coded distance a of 2.0 was adopted for the center points to the axial points.

\subsection{Experimental procedure}

To perform the experiments, the equipment used included a welding machine ESAB AristoPower 460, a module AristoFeed 30-4 watt MA6 (employed to feed the wire), and a mechanical system device. The latter was used to control the welding speed and the torch position (distance and angle). The shielding gas used was a mixture of $75 \% \mathrm{Ar}+25 \% \mathrm{CO}_{2}$ at a flow rate of $16 \mathrm{~L} / \mathrm{min}$. The torch angle was set at $15^{\circ}$ to "pushing". The base metal was carbon steel AISI 1020, cut into plates of $120 \times 60 \times 6.35 \mathrm{~mm}$. The filler metal employed was a flux-cored stainless steel wire type AWS E316LT1-1/4, with a diameter of $1.2 \mathrm{~mm}$. Table 2 presents the chemical composition of these materials.

\subsection{Electrochemical corrosion testing}

The electrochemical tests, potentiodynamic anodic polarization and double loop electrochemical potentiokinetic reactivation (DLEPR), were performed with an EmStat potentiostat, model PalmSens. A three-electrode set-up cell was used, with a saturated calomel electrode (SCE) as the reference electrode, a platinum electrode as the counter electrode, and the specimen as the working electrode. The electrolytes were maintained at $30 \pm 2{ }^{\circ} \mathrm{C}$ during tests. Before the electrochemical tests, an electrical contact of the specimen was made by spot welding a copper lead on to the back of the specimen and the samples were mounted in epoxy resin. Prior to each test, the samples were polished with 600 -grit papers. A polymeric coating was applied to cover the sample surface, except on the cladding metal. Three replicate tests of each measurement were performed.

Potentiodynamic anodic polarization test was performed to evaluate the pitting corrosion resistance of the claddings. The test solution was $3.5 \mathrm{wt} \% \mathrm{NaCl}$ aqueous solution. A potential scan was applied beginning at $-600 \mathrm{mV}$ and continued in more noble direction to $400 \mathrm{mV}$ at a rate of $0.3 \mathrm{mVs}^{-1}$. To yield a steady-state condition, the open circuit potential was recorded for $50 \mathrm{~min}$. Pitting potential $\left(E_{p i t}\right)$ was defined as the potential at which current density began to increase continuously ${ }^{25}$. Higher the pitting potential better will be the resistance of the material to pitting corrosion ${ }^{26}$.

Table 1. Welding parameters and their levels.

\begin{tabular}{lccccccc}
\hline \multirow{2}{*}{ Input parameters } & \multirow{2}{*}{ Units } & \multirow{2}{*}{ Symbol } & \multicolumn{5}{c}{ Levels } \\
\cline { 4 - 9 } & & & $\mathbf{- 2}$ & $\mathbf{- 1}$ & $\mathbf{0}$ & $+\mathbf{1}$ & $+\mathbf{2}$ \\
\hline Wire feed rate & $\mathrm{m} / \mathrm{mm}$ & $\mathrm{W}$ & 5.5 & 7.0 & 8.5 & 10.0 & 11.5 \\
\hline Welding Voltage & $\mathrm{V}$ & $\mathrm{V}$ & 24.5 & 27.0 & 29.5 & 32.0 & 34.5 \\
\hline Welding Speed & $\mathrm{cm} / \mathrm{min}$ & $\mathrm{S}$ & 20 & 30 & 40 & 50 & 60 \\
\hline Nozzle to plate distance & $\mathrm{mm}$ & $\mathrm{N}$ & 10 & 15 & 20 & 25 & 30 \\
\hline
\end{tabular}

Table 2. Chemical composition of base metal and filler metal.

\begin{tabular}{llllllllll}
\hline \multirow{2}{*}{ Material } & \multicolumn{9}{c}{ Element (wt. \%) } \\
\cline { 2 - 10 } & \multicolumn{1}{c}{$\mathbf{C}$} & Mn & P & S & Si & Ni & Cr & Mo \\
\hline AISI 1020 & $0.18 / 0.23$ & $0.30 / 0.60$ & 0.04 & 0.05 & - & - & - & - \\
\hline AWS E316LT1-1/4 & 0.03 & 1.58 & - & - & 1.00 & 12.4 & 18.5 & 2.46 \\
\hline
\end{tabular}


Table 3. Design matrix and responses.

\begin{tabular}{|c|c|c|c|c|c|c|}
\hline \multirow{2}{*}{ Run } & \multicolumn{4}{|c|}{ Parameters } & \multicolumn{2}{|c|}{ Responses } \\
\hline & $W(\mathrm{~m} / \mathrm{min})$ & $T(\mathbf{V})$ & $S(\mathrm{~cm} / \mathrm{min})$ & $N(\mathbf{m m})$ & DOS & $E_{p i t}(\mathrm{mV})$ \\
\hline 1 & -1 & -1 & -1 & -1 & 0.138 & 193 \\
\hline 2 & 1 & -1 & -1 & -1 & 0.094 & 165 \\
\hline 3 & -1 & 1 & -1 & -1 & 0.383 & 160 \\
\hline 4 & 1 & 1 & -1 & -1 & 0.698 & 180 \\
\hline 5 & -1 & -1 & 1 & -1 & 0.876 & 145 \\
\hline 6 & 1 & -1 & 1 & -1 & 0.491 & 136 \\
\hline 7 & -1 & 1 & 1 & -1 & 0.870 & 155 \\
\hline 8 & 1 & 1 & 1 & -1 & 0.891 & 126 \\
\hline 9 & -1 & -1 & -1 & 1 & 0.005 & 255 \\
\hline 10 & 1 & -1 & -1 & 1 & 0.002 & 266 \\
\hline 11 & -1 & 1 & -1 & 1 & 0.052 & 204 \\
\hline 12 & 1 & 1 & -1 & 1 & 0.005 & 242 \\
\hline 13 & -1 & -1 & 1 & 1 & 0.095 & 177 \\
\hline 14 & 1 & -1 & 1 & 1 & 0.004 & 259 \\
\hline 15 & -1 & 1 & 1 & 1 & 0.518 & 155 \\
\hline 16 & 1 & 1 & 1 & 1 & 0.169 & 165 \\
\hline 17 & -2 & 0 & 0 & 0 & 0.318 & 218 \\
\hline 18 & 2 & 0 & 0 & 0 & 0.118 & 190 \\
\hline 19 & 0 & -2 & 0 & 0 & 0.081 & 221 \\
\hline 20 & 0 & 2 & 0 & 0 & 0.876 & 144 \\
\hline 21 & 0 & 0 & -2 & 0 & 0.002 & 275 \\
\hline 22 & 0 & 0 & 2 & 0 & 0.689 & 128 \\
\hline 23 & 0 & 0 & 0 & -2 & 0.893 & 138 \\
\hline 24 & 0 & 0 & 0 & 2 & 0.001 & 260 \\
\hline 25 & 0 & 0 & 0 & 0 & 0.369 & 223 \\
\hline 26 & 0 & 0 & 0 & 0 & 0.375 & 226 \\
\hline 27 & 0 & 0 & 0 & 0 & 0.287 & $*$ \\
\hline 28 & 0 & 0 & 0 & 0 & 0.236 & 238 \\
\hline 29 & 0 & 0 & 0 & 0 & 0.185 & 249 \\
\hline 30 & 0 & 0 & 0 & 0 & 0.173 & 219 \\
\hline 31 & 0 & 0 & 0 & 0 & 0.180 & 228 \\
\hline
\end{tabular}

The susceptibility to intergranular corrosion of cladding was evaluated using the double loop electrochemical potentiokinetic reactivation (DLEPR) tests, following ASTM G108 - $94^{27}$ standards. The electrolyte was $0.5 \mathrm{M}$ $\mathrm{H}_{2} \mathrm{SO}_{4}+0.01 \mathrm{M} \mathrm{KSCN}$. Specimens were immersed into solution for $5 \mathrm{~min}$ to obtain corrosion potential. Then it was polarized anodically to $250 \mathrm{mV}$ at $1.67 \mathrm{mV} / \mathrm{s}$. As the maximum potential was reached, the scanning direction was reversed and the potential decreased at the same scan rate to the original potential. The degree of sensitization $(D O S)$ was evaluated by the reactivation ratio $\left(I_{r} / I_{a}\right)$ where $I_{r}$ is the reactivation (cathodic) current density peak and $I_{a}$ is the activation (anodic) current density one ${ }^{28-30}$. The higher the ratio, the higher the degree of sensitization ${ }^{28}$. The average values of pitting potential and degree of sensitization for the 31 samples are presented in the experimental matrix, as shown in Table 3. The pitting potential of test 27 was characterized as outlier and removed from the study.

\subsection{Microstructure analysis}

Surface preparations were carried out by wet grinding with a series of $\mathrm{SiC}$ papers to 2000-grit and then polished with $1 \mu \mathrm{m}$ alumina suspension. The metallographic characterization of claddings was performed by using electrolytic etching in $10 \mathrm{wt} . \%$ oxalic acid aqueous solution, according to ASTM A $262-13^{31}$, Practice A.

The ferrite content was measured using a Fisher Ferritescope (magnetic induction method), model FMP30. The results of Ferritoscope measurement were reported as ferrite number (FN). Microhardness measurements were made using Vickers hardness tester with $300 \mathrm{gf}$ load applied for $10 \mathrm{~s}$ duration. The average of 5 readings was reported.

The dilution percentage was calculated by dividing the penetration area by the total area. The samples were cut and their cross sections were prepared and then attacked with $4 \%$ nital. The image analysis software Analysis Doc was utilized to measure the weld bead dimensions.

\section{Results and Discussion}

\subsection{Microstructure analysis}

From Table 3, it was observed that sample 8 showed the highest degree of sensitization and the lowest pitting potential and the sample 21 showed the lowest degree of sensitization and the highest pitting potential. This difference between the samples facilitated the analysis and comparison 
a)

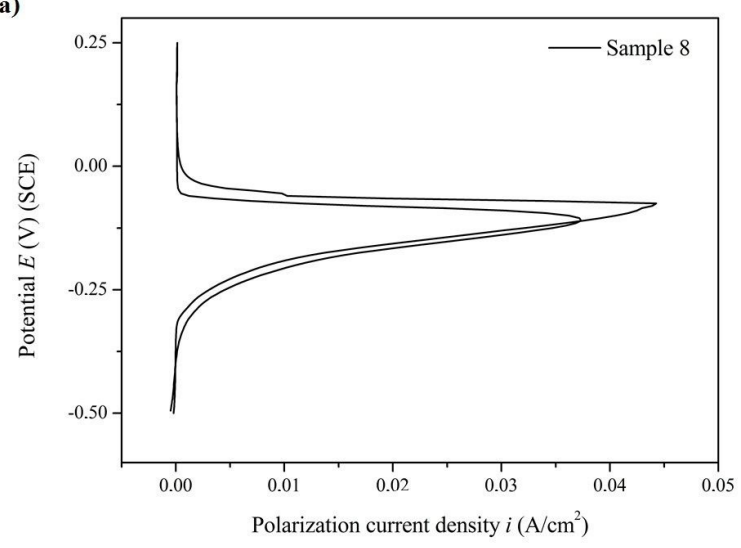

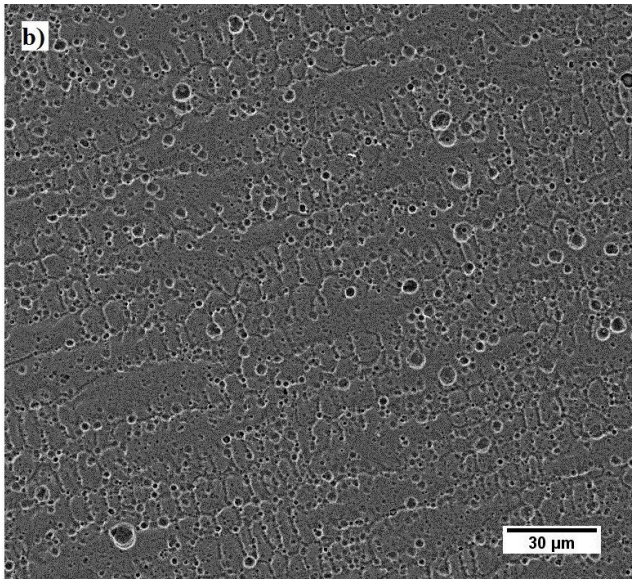

Figure 1. Characterization of sample 8: (a) DLEPR polarization curve and (b) microstructure of cladding (SEM examination).
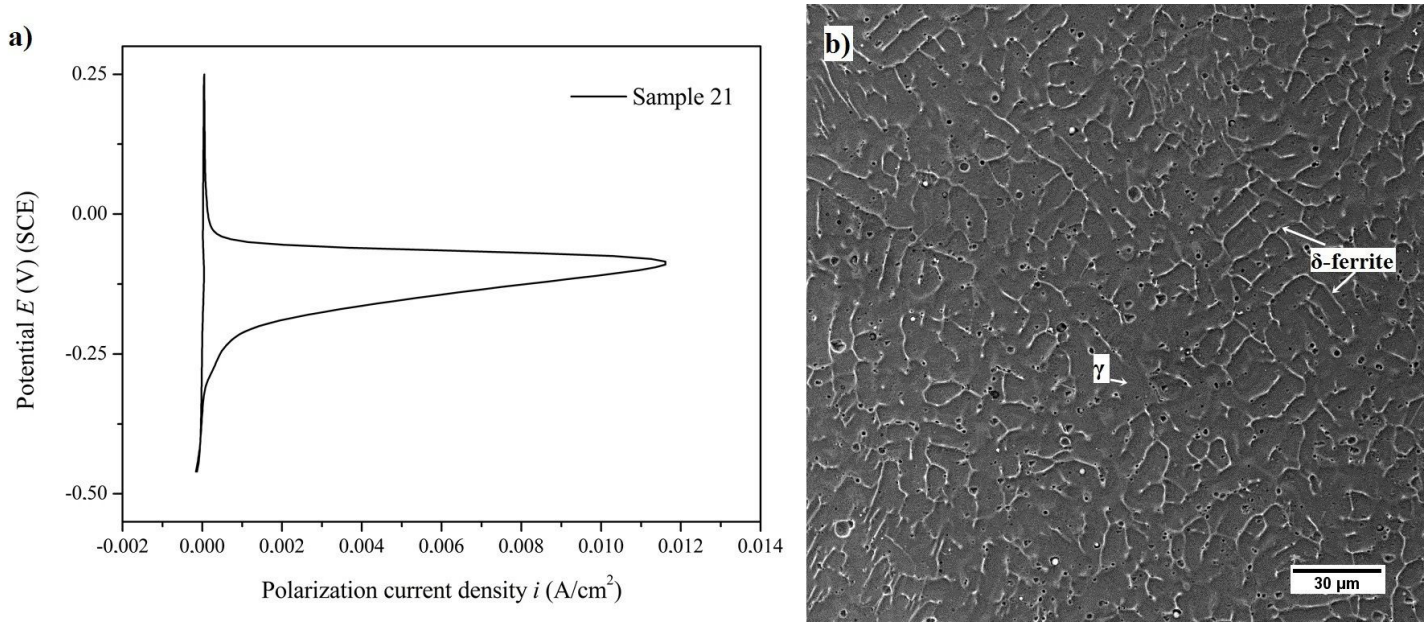

Figure 2. Characterization of sample 21: (a) DLEPR polarization curve and (b) microstructure of cladding (SEM examination).

Table 4. Dilution results and chemical composition of the weld metal (wt. \%) estimated by Schaeffler diagram.

\begin{tabular}{cccccccccc}
\hline Weld metal & Dilution & $\mathbf{C}$ & $\mathbf{M n}$ & $\mathbf{C r}$ & $\mathbf{N i}$ & $\mathbf{M o}$ & $\mathbf{S i}$ & $\mathbf{N i}_{\text {eq }}$ & $\mathbf{C r}_{\text {eq }}$ \\
\hline Sample 21 & $18.6 \%$ & 0.06 & 1.37 & 15.1 & 10.1 & 2.00 & 0.81 & 12.6 & 18.3 \\
\hline Sample 8 & $41.1 \%$ & 0.10 & 1.12 & 10.9 & 7.30 & 1.45 & 0.59 & 10.9 & 13.2 \\
\hline
\end{tabular}

Table 5. Results of microhardness (HV) and ferrite number (FN) in the weld metal.

\begin{tabular}{cccc}
\hline Weld metal & Ferritoscope (FN) & Schaeffler (FN) & HV \\
\hline Sample 21 & $3.38 \%$ & $0-5 \%$ & $159.1 \mathrm{HV}$ \\
\hline Sample 8 & $52.6 \%$ & - & $351.7 \mathrm{HV}$ \\
\hline
\end{tabular}

between the microstructures of the claddings. Thus, only the microstructure of sample 8 and 21 were analyzed.

The dilution level (D) was used to estimate the chemical composition in the fusion zone, it was determined by Equation 1.

$X_{W M}=X_{B M} \frac{D}{100}+X_{F M}\left(1-\frac{D}{100}\right)$

where $\mathrm{X}_{\mathrm{WM}}, \mathrm{X}_{\mathrm{BM}}$ and $\mathrm{X}_{\mathrm{FM}}$ are the content of element " $\mathrm{X}$ " in the weld metal, base metal and filler metal, respectively.

Based on the equations in Schaeffler diagram $\left(\mathrm{Cr}_{\mathrm{eq}} / \mathrm{Ni}_{\mathrm{eq}}\right.$, where the $\mathrm{Cr}_{\text {eq }}=\mathrm{Cr}$ wt. $\%+$ Mo wt. $\%+1.5 \mathrm{Si}$ wt.\% ${ }^{+}$
$0.5 \mathrm{Nb}$ wt. $\%$ and the $\mathrm{Ni}_{\text {eq }}=\mathrm{Ni}$ wt. $\%+30 \mathrm{C}$ wt. $\%+$ $0.5 \mathrm{Mn} w \mathrm{w} . \%$ ) and chemical composition of the weld metal, $\mathrm{Cr}_{\text {eq }}$ and $\mathrm{Ni}_{\text {eq }}$ were calculated and are shown in Table 4. $\mathrm{Cr}_{\mathrm{eq}}$ and $\mathrm{Ni}_{\mathrm{eq}}$ reduced when compared to the pure filler metal $\left(\mathrm{Cr}_{\mathrm{eq}}=22.5 \%\right.$ and $\left.\mathrm{Ni}_{\mathrm{eq}}=14.1 \%\right)$. This reduction is attributed to the absence of chromium, molybdenum and nickel in the base metal. It is also observed that the carbon content increases with dilution while other alloy elements decrease.

The $\delta$-ferrite also was estimated by Schaeffler diagram, as shown in Table 5. The results indicated that the $\delta$-ferrite contents decrease when the dilution increase. This is due to the reduction of ferritizing elements in the weld metal. Based on the diagram, the sample 21 contains between 0 and $5 \%$ of ferrite, while the sample 8 is composed by austenite and martensite.

Figure 1 and Figure 2 show the curves of DLEPR test and the microstructures of samples 8 and 21 respectively. Sample 8 presented a much higher degree of sensitization 
$(\mathrm{DOS}=0.891)$ than sample $21(\mathrm{DOS}=0.002)$. From Figure $1 \mathrm{~b}$, a large number of holes (ditches) caused by detachment of precipitates are observed, confirming the result of the DLEPR test (Figure 1a). This result may be due to high heat input at sample 8 . The high heat input and the low cooling rate induce the mixing and the segregation of alloying elements and the formation of chromium-depleted zones, resulting in the degradation of the resistance to localized corrosion ${ }^{32}$.

As Figure $2 \mathrm{~b}$ shows the microstructure of the weld zone of sample 21 possesses only a few ditches. In this sample, the presence of $\delta$-ferrite was also observed. This fact is expectable since fast cooling in welding does not

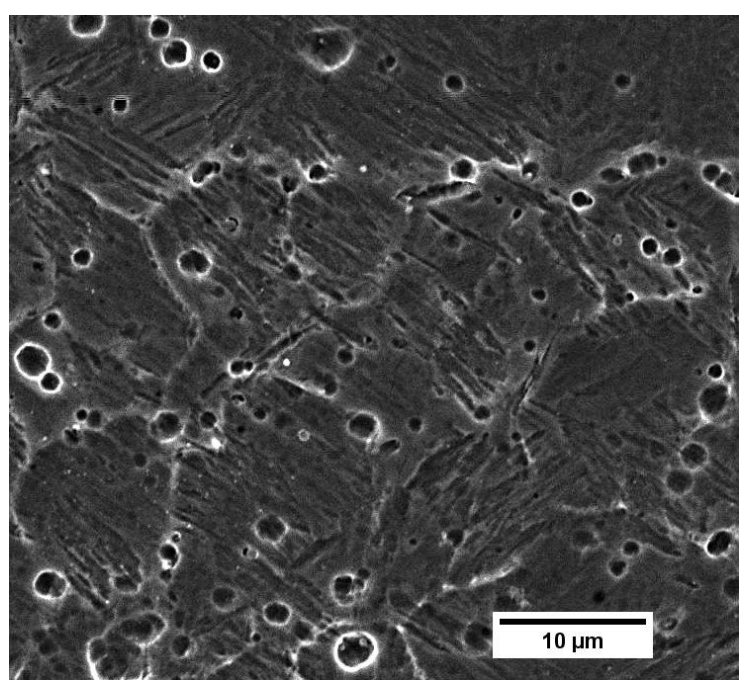

Figure 3. SEM observation of sample 8 (weld metal).

Table 6. Full model coefficients.

\begin{tabular}{ccc}
\hline Coefficients & DOS & $\boldsymbol{E}_{\text {pit }}$ \\
\hline$\beta_{0}$ & $\mathbf{0 . 2 5 7 9}$ & $\mathbf{2 3 0 . 5 0}$ \\
\hline$\beta_{1}$ & -0.0409 & 1.625 \\
\hline$\beta_{2}$ & $\mathbf{0 . 1 4 4 6}$ & $\mathbf{- 1 5 . 1 2 5}$ \\
\hline$\beta 3$ & $\mathbf{0 . 1 6 2 9}$ & $\mathbf{- 2 6 . 7 0 8}$ \\
\hline$\beta_{4}$ & $\mathbf{- 0 . 2 2 3 9}$ & $\mathbf{2 9 . 4 5 8}$ \\
\hline$\beta_{1}{ }^{2}$ & -0.0169 & $\mathbf{- 8 . 3 4 4}$ \\
\hline$\beta_{2}{ }^{2}$ & $\mathbf{0 . 0 4 8 2}$ & $\mathbf{- 1 3 . 7 1 9}$ \\
\hline$\beta_{3}{ }^{2}$ & 0.0149 & $\mathbf{- 8 . 9 6 9}$ \\
\hline$\beta_{4} \beta_{1}$ & 0.0403 & $\mathbf{- 9 . 5 9 4}$ \\
\hline$\beta_{1} \beta_{3}$ & 0.0289 & -1.063 \\
\hline$\beta_{1} \beta_{4}$ & $\mathbf{- 0 . 0 6 4 1}$ & 0.813 \\
\hline$\beta_{2} \beta_{3}$ & -0.0248 & $\mathbf{1 1 . 6 8 7}$ \\
\hline$\beta_{2} \beta_{4}$ & 0.0052 & -1.437 \\
\hline$\beta_{3} \beta_{4}$ & -0.0378 & $\mathbf{- 1 0 . 8 1 3}$ \\
\hline & $\mathbf{- 0 . 0 6 8 3}$ & -4.688 \\
\hline
\end{tabular}

* Bold values represent the individually significant terms $(P$-value $<5 \%)$. last enough time to complete transformation of ferrite $(\delta)$ to austenite $(\gamma)$ (FA solidification). According to Lee et al. ${ }^{33}$ and Kim et al. ${ }^{34}$, the solidification mode of austenite stainless steel could be predicted by Schaeffler equation. From Table 2, $\mathrm{Cr} / \mathrm{Ni}$ equivalent ratio of $316 \mathrm{~L}$ stainless steel in our study was 1.6, which indicated the formation of FA mode during solidification ${ }^{10}$. The FA mode began with primarily ferrite, and uncompleted $\delta-\gamma$ phase transformation occurred during the solidification of the welding pool, which resulted in the formation of the retained ferrite in the cladding. No $\delta$-ferrite was observed in sample 8 , which accords with the result indicated in Table 5. However, in Figure 3, it can be seen that sample 8 showed microstructure with a lath appearance, being this characteristic aspect of the martensitic microstructure.

The results of Ferritoscope and microhardness measurements are presented in Table 5. It is observed that the sample 21 presented $3.5 \mathrm{FN}$, which is in accordance with the value predicted in the Schaeffler diagram. It is recommended the presence of delta-ferrite in the austenitic stainless steel welds to prevent hot cracking. The high value of FN (52.6\%) and hardness (351.7 HV) in sample 8 are attributed to the presence of martensite in the weld zone. The Ferritoscope can be used to detect different magnetic phase $^{35}$. The martensite phase is ferromagnetic and, thus, can also be quantified by magnetic measurements ${ }^{36}$. This phase may have been formed due to high dilution and increased carbon concentration in the cladding. The high hardness also can be attributed to the chromium carbides precipitation. The low corrosion resistance in sample 8 as compared to sample 21 is attributed to the higher dilution and the presence of martensite and carbides in the cladding.

\subsection{Modeling of the stainless steel cladding process}

The second order response surface model was used to represent the approximate relationship between the responses and the welding parameters, according to Equation 2.

$$
\begin{aligned}
& Y=\beta_{0}+\beta_{1} W+\beta_{2} V+\beta_{3} S+\beta_{4} N+\beta_{11} W^{2}+\beta_{22} V^{2}+\beta_{33} S^{2}+ \\
& \beta_{44} N^{2}+\beta_{12} W V+\beta_{13} W S+\beta_{14} W N+\beta_{23} V S+\beta_{24} V N+\beta_{34} S N
\end{aligned}
$$

where $Y$ is the response of interest, where $\beta_{0}$ is the free term of the regression equation, the coefficients $\beta_{1}, \beta_{2}, \beta_{3}$ and $\beta_{4}$ are linear terms, the coefficients $\beta_{11}, \beta_{22}, \beta_{33}$ and $\beta_{44}$ are the quadratic terms, and the coefficients $\beta_{12}, \beta_{13}, \beta_{14}, \beta_{23}, \beta_{24}$ and $\beta_{34}$ are the interaction terms, $W, V, S$, and $N$ are the input parameters expressed in their coded form.

The Ordinary Least Squares (OLS) algorithm, through the statistical software Minitab, was applied to develop the full quadratic models of each response. The estimated coefficients are given in Table 6. Then, the ANOVA procedure was applied to check the adequacies of the models as well as their adjustments, as shown in Table 7 . Since all regression

\begin{tabular}{|c|c|c|c|c|c|c|c|c|c|c|}
\hline \multirow{2}{*}{ Responses } & \multicolumn{2}{|c|}{ Degrees of freedom } & \multicolumn{2}{|c|}{ Sum of squares } & \multicolumn{2}{|c|}{ Mean square } & \multirow{2}{*}{$F$} & \multirow{2}{*}{$P$} & \multirow{2}{*}{ Lack-of-fit } & \multirow{2}{*}{ Adj. $R^{2}$} \\
\hline & RG & RS & RG & RS & RG & RS & & & & \\
\hline DOS & 14 & 16 & 2.6937 & 0.0459 & 0.1924 & 0.0076 & 13.11 & 0.000 & 0.141 & $85.00 \%$ \\
\hline$E_{p i t}$ & 14 & 15 & 56458.6 & 613.5 & 4032.8 & 122.7 & 9.78 & 0.000 & 0.054 & $80.90 \%$ \\
\hline
\end{tabular}

Table 7. ANOVA for the models developed.

* RG- Regression, RS- Residual. Tabulated values of F: $\mathrm{F}_{0.05}(14,16)=2.37 ; \mathrm{F}_{0.05}(14,15)=2.42$. 

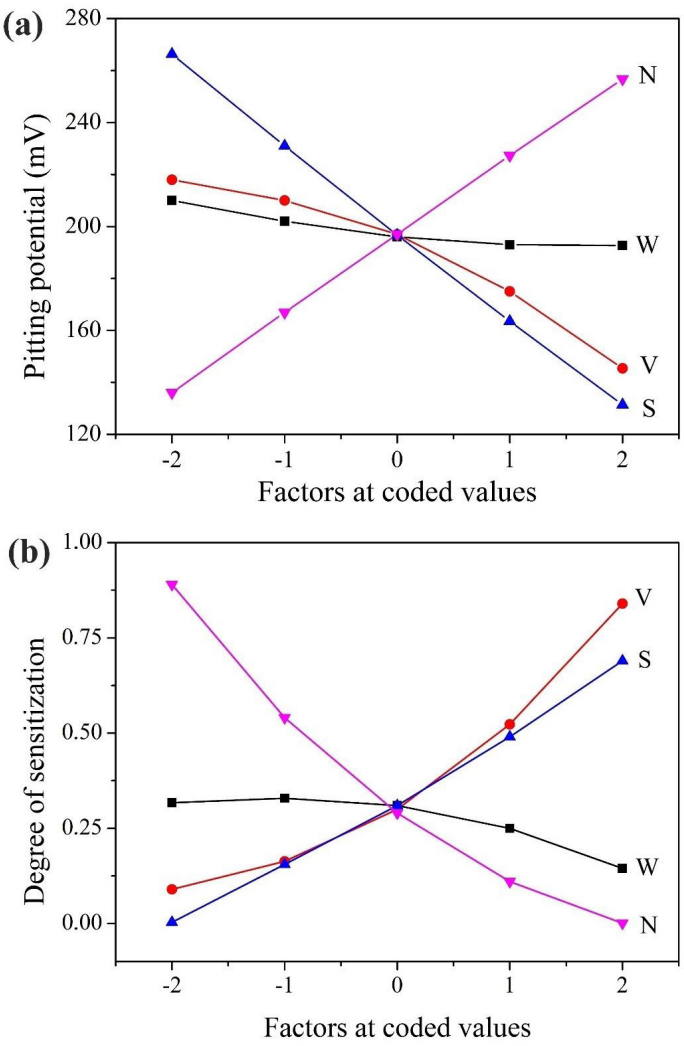

Figure 4. Effect of nozzle to plate distance $(N)$, wire feed rate $(W)$, welding voltage $(V)$ and welding speed $(S)$ on: (a) pitting potential and (b) degree of sensitization.

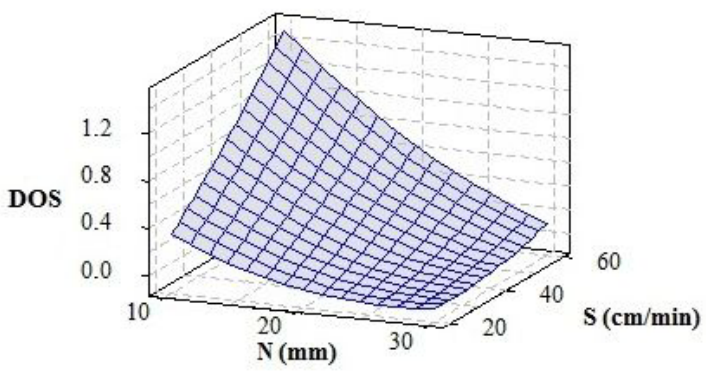

Figure 5. Response surface for interaction effect of welding speed $(S)$ and nozzle to plate distance $(N)$ on degree of sensitization $(D O S)$ $(W=8.5 \mathrm{~m} / \mathrm{min} ; V=29.5 \mathrm{~V})$.

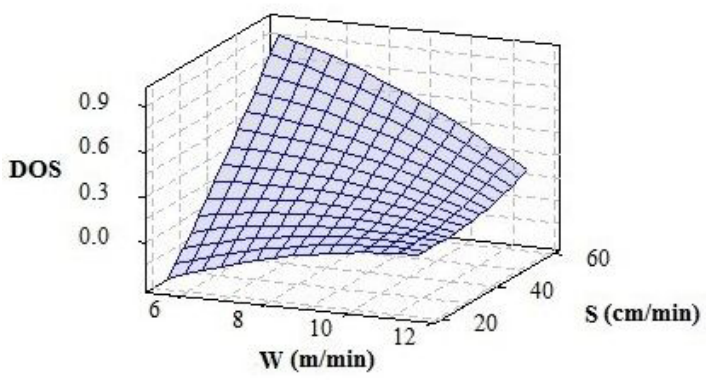

Figure 6. Response surface for interaction effect of welding speed $(S)$ and wire feed rate $(W)$ on degree of sensitization $(D O S)$ $(N=20 \mathrm{~mm} ; V=29.5 \mathrm{~V})$.
$P$-values were less than $5 \%$ of significance, it can be seen that all expressions are adequate. All models presented adj. $R^{2}$ values above $80.0 \%$ indicating a good adequacy for all expressions and no lack of fit was observed. Therefore, the developed models can be used for predicting the cladding process.

\subsection{Effect of process parameters on pitting potential and degree of sensitization}

The direct effect of the process parameters on pitting potential and degree of sensitization are presented in Figure 4. The pitting and intergranular corrosion resistance increased with nozzle to plate distance $(N)$ while it decreases with increase in welding speed $(S)$ and welding voltage $(V)$. This may be due to the fact that the heat input increases with an increase in welding voltage, and it decreases with an increase in nozzle to plate distance. The high heat input enhances the diffusion of alloying elements between carbon steel and stainless steel and contributes to the formation of chromium carbides. An increase in the welding speed decreases the heat input; however, it was observed that at high values of speed the dilution increased, causing a decrease in pitting potential and increase in degree of sensitization. The wire feed rate $(W)$ does not much affect the response in any levels, this shows that it is an insignificant factor for pitting potential and degree of sensitization.

\subsection{Interaction effect of process parameters on degree of sensitization}

Figure 5 shows the interaction effect of nozzle to plate distance $(N)$ and welding speed $(S)$ on degree of sensitization $(D O S)$. From the figure, it is evident that DOS decreases with decrease in welding speed for all levels of nozzle to plate distance. It was also observed that the welding speed had a considerable effect on $D O S$ when small values of nozzle to plate distance $(10 \mathrm{~mm})$ was used. At $30 \mathrm{~mm}$, the effect of welding speed is not much significant. At the lower values of $N$, welding speed has dominant effect over the degree of sensitization. However, at the higher values of $S, N$ is the dominant factor in determining the degree of sensitization, and therefore, DOS decreases with increasing nozzle to plate distance.

Although the wire feed rate $(W)$ has no significant effect on $D O S$, the interaction of this parameter with the welding speed is significant, as shown in Figure 6. It was observed that the degree of sensitization increases considerably when higher values of welding speeds and lower values of wire feed rate are used. This may be due to the fact that the deposition rate of filler material decreases with increase in welding speed and reduction in wire feed rate, resulting in higher dilution. Increase in dilution enhances the carbon content and reduces the chromium content of the claddings resulting in high DOS.

\subsection{Interaction effect of process parameters on pitting potential}

Figure 7 shows the interaction effect of nozzle to plate distance $(N)$ and welding voltage $(V)$ on pitting potential $\left(E_{p i t}\right)$. It was observed that higher pitting potentials are achieved using lower values of welding voltages (about 27V) and 


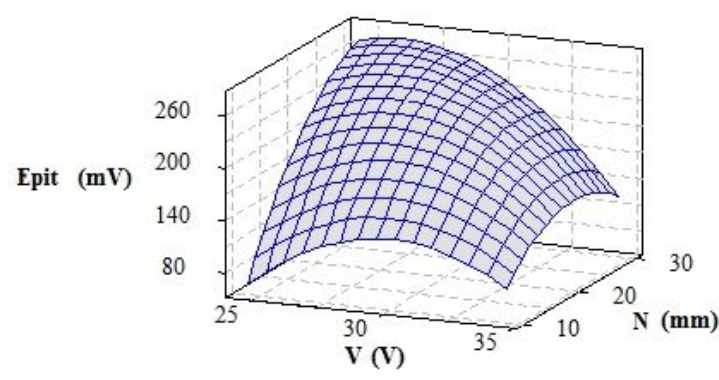

Figure 7. Response surface for interaction effect of welding voltage $(V)$ and nozzle to plate distance $(N)$ on pitting potential $\left(E_{p i t}\right)$ $(W=8.5 \mathrm{~m} / \mathrm{min} ; S=40.0 \mathrm{~cm} / \mathrm{min})$.

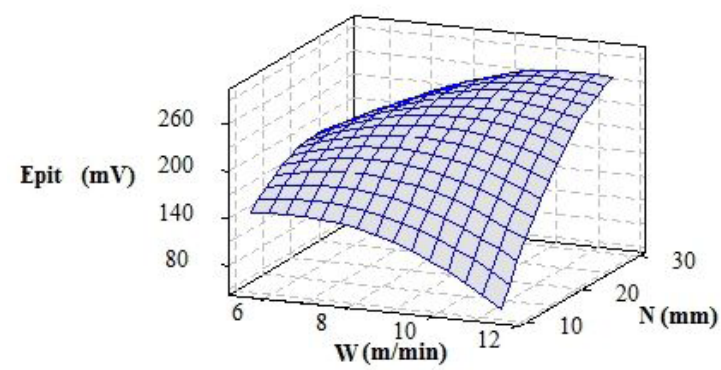

Figure 8. Response surface for interaction effect of wire feed rate $(W)$ and nozzle to plate distance $(N)$ on pitting potential $\left(E_{p i t}\right)$ $(V=29.5 \mathrm{~V} ; S=40.0 \mathrm{~cm} / \mathrm{min})$.

higher values of nozzle to plate distances. This effect can be assigned to a reduction in heat input. From the figure, it is also observed that the nozzle to plate distance had a considerable effect on $E_{p i t}$ when lower values of welding voltage were used.

From Figure 8, it was observed that the cladding showed higher pitting corrosion resistance when higher values of $W$ and $N$ were used. This effect is attributed to an increase in electrode melting rate when the wire feed rate is increased. Moreover, the increase of nozzle to plate distance causes the filler material to accumulate over the base metal, which results in lower dilution and higher pitting potential.

\section{Conclusions}

Cladding process is an excellent alternative for the production of corrosion resistant surfaces; however, welding parameters must be controlled. The microstructural characterization showed the presence of precipitates, martensite and $\delta$-ferrite phase in the claddings. The high heat input induces the segregation of alloying elements and the formation of precipitates and martensite, resulting in the degradation of the resistance to localized corrosion. Regression models were developed using response surface methodology to predict the pitting potential and the degree of sensitization for cladding of 316L flux-cored wire onto AISI 1020 carbon steel plates. The mathematical models developed presented high adjustments and can be characterized as expressions of great reliability. All RSM models were adjusted over $80 \%$. Among the parameters analyzed only the wire feed rate had no significant effect on the corrosion resistance of the claddings. The pitting and intergranular corrosion resistance can be maximized by employing low welding speeds, low welding voltages and high nozzle to plate distances. Also, it was observed that interaction effects have considerable influence over the corrosion resistance and their effects cannot be neglected. A parameter with little influence on its own, such as the wire feed rate, can produce significant effects when combined with another parameter.

\section{Acknowledgement}

The authors of this work would like to thank the financial support by the Brazilian agency CAPES.

\section{References}

1. ASM International. Properties and selection: irons, steel and high performance alloys: carbon and low-alloy steel sheet and strip. Materials Park: ASM International; 2005. p. 334-54. (vol. $1)$.

2. Gomes GF, Ueda M, Beloto AF, Nakazato RZ, Reuther H. Corrosion resistance enhancement of SAE 1020 steel after Chromium implantation by nitrogen ion recoil. Mater Res. 2005;8(4):387-9. http://dx.doi.org/10.1590/S1516-14392005000400005.

3. Moura V, Ribeiro I, Moriggi P, Capão A, Salles C, Bitati S, et al. The influence of surface microbial diversity and succession on microbiologically influenced corrosion of steel in a simulated marine environment. Arch Microbiol. 2018;200(10):1447-56. http://dx.doi.org/10.1007/s00203-018-1559-2.

4. Palani PK, Murugan N. Optimization of weld bead geometry for stainless steel claddings deposited by FCAW. J Mater Process Technol. 2007;190(1-3):291-9. http://dx.doi.org/10.1016/j. jmatprotec.2007.02.035.

5. Jayachandran JAR, Murugan N. Development of eco-friendly surface modification process for $316 \mathrm{~L}$ austenitic stainless steel weld cladding. Surf Eng. 2012;28(1):5-10. http://dx.doi.org/1 0.1179/1743294411Y.0000000025.

6. Besliu MM, Voiculescu I, Solomon G. Effects of dilution on weld overlays realized with flux-cored arc welding (FCAW) process using 309LV filler metal on the S235JR steel. UPB Sci Bull. 2017;79(1):172-82.

7. Senthilkumar B, Kannan T, Madesh R. Optimization of fluxcored arc welding process parameters by using genetic algorithm. Int J Adv Manuf Technol. 2017;93(1-4):35-41. http://dx.doi. org/10.1007/s00170-015-7636-7.

8. Gomes JHF, Costa SC, Paiva AP, Balestrassi PP. Mathematical modeling of weld bead geometry, quality, and productivity for stainless steel claddings deposited by FCAW. J Mater Eng Perform. 2012;21(9):1862-72. http://dx.doi.org/10.1007/ s11665-011-0103-1.

9. De Tiedra P, Martín O, García C, Martín F, López M. Effect of prior cold work on the degree of sensitisation of welded joints of AISI $316 \mathrm{~L}$ austenitic stainless steel studied by using an electrochemical minicell. Corros Sci. 2012;54:153-60. http:// dx.doi.org/10.1016/j.corsci.2011.09.010.

10. Bansod AV, Patil AP, Moon AP, Shukla S. Microstructural and electrochemical evaluation of fusion welded low-nickel and 304 SS at different heat input. J Mater Eng Perform. 2017;26(12):5847-63. http://dx.doi.org/10.1007/s11665-0173054-3.

11. Yoganandh J, Kannan T, Kumaresh Babu SP, Natarajan S. Optimization of GMAW process parameters in austenitic stainless steel cladding using genetic algorithm based computational models. Exp Tech. 2013;37(5):48-58. http:/ dx.doi.org/10.1111/j.1747-1567.2011.00803.x.

12. Prabhu R, Alwarsamy T. Effect of process parameters on ferrite number in cladding of $317 \mathrm{~L}$ stainless steel by pulsed 
MIG welding. J Mech Sci Technol. 2017;31(3):1341-7. http:// dx.doi.org/10.1007/s12206-017-0234-x.

13. Lippold JC, Kotecki DJ. Welding metallurgy and weldability of stainless steels. New Jersey: John Wiley \& Sons; 2005.

14. Palani PK, Murugan N. Modelling and analysis of pitting corrosion resistance of stainless steel overlays deposited by flux cored arc welding process. Surf Eng. 2008;24(6):422-8. http://dx.doi.org/10.1179/174329408X281867.

15. Dadfar M, Fathi MH, Karimzadeh F, Dadfar MR, Saatchi A. Effect of TIG welding on corrosion behavior of $316 \mathrm{~L}$ stainless steel. Mater Lett. 2007;61(11-12):2343-6. http://dx.doi. org/10.1016/j.matlet.2006.09.008.

16. Eghlimi A, Shamanian M, Raeissi K. Effect of current type on microstructure and corrosion resistance of super duplex stainless steel claddings produced by the gas tungsten arc welding process. Surf Coat Tech. 2014;244:45-51. http://dx.doi.org/10.1016/j. surfcoat.2014.01.047.

17. Shahi AS, Pandey S. Modelling of the effects of welding conditions on dilution of stainless steel claddings produced by gas metal arc welding procedures. J Mater Process Technol. 2008;196(13):339-44. http://dx.doi.org/10.1016/j.jmatprotec.2007.05.060.

18. Rajkumar GB, Murugan N. Development of regression models and optimization of FCAW process parameter of 2205 duplex stainless steel. Indian J Eng Mater Sci. 2014;21:149-54.

19. Palani PK, Murugan N. Prediction of delta ferrite content and effect of welding process parameters in claddings by FCAW. Mater Manuf Process. 2006;21(5):431-8. http://dx.doi. org/10.1080/10426910500471409.

20. Balan AV, Kannan T, Shivasankaran N. Effect of FCAW process parameters on bead geometry in super duplex stainless steel claddings. Int J App Eng Res. 2014;9(24):27331-46.

21. Senthilkumar B, Kannan T. Effect of flux cored arc welding process parameters on bead geometry in super duplex stainless steel claddings. Measurement. 2015;62:127-36. http://dx.doi. org/10.1016/j.measurement.2014.11.007.

22. Balan AV, Shivasankaran N, Magibalan S. Optimization of cladding parameters for resisting corrosion on low carbon steels using simulated annealing algorithm. Mater Res Express. 2018;5(4):046527. http://dx.doi.org/10.1088/2053-1591/aab7cb.

23. Murugan N, Kannan T. Effects of flux cored arc welding parameters on pitting corrosion resistance of duplex stainless steel clad metals. Corros Eng Sci Technol. 2007;42(1):29-35. http://dx.doi.org/10.1179/174327807X159952.

24. Montgomery DC. Design and analysis of experiments. 6th ed. New York: John Wiley \& Sons; 2005.

25. Zhu P, Cao X, Wang W, Zhao J, Lu Y, Shoji T. An investigation on microstructure and pitting corrosion behavior of $316 \mathrm{~L}$ stainless steel weld joint. J Mater Res. 2017;32(20):3904. http://dx.doi. org/10.1557/jmr.2017.316.
26. Siva K, Murugan N. A Study on the Influence of PTAW Process Parameters on Pitting Corrosion Resistance of Nickel Based Overlays. Procedia Eng. 2013;64:1147-56. http://dx.doi. org/10.1016/j.proeng.2013.09.193.

27. American Society for Testing and Materials. ASTM G108-94: standard test method for Electrochemical Reactivation (EPR) for detecting sensitization of AISI Type 304 and 304L stainless steels. Philadelphia: ASTM International; 2015.

28. Li S-X, He Y-N, Yu S-R, Zhang P-Y. Evaluation of the effect of grain size on chromium carbide precipitation and intergranular corrosion of 316L stainless steel. Corros Sci. 2013;66:211-6. http://dx.doi.org/10.1016/j.corsci.2012.09.022.

29. Li S-X, Li L, Yu S-R, Akid R, Xia H-B. Investigation of intergranular corrosion of $316 \mathrm{~L}$ stainless steel diffusion bonded joint by electrochemical potentiokinetic reactivation. Corros Sci. 2011;53(1):99-104. http://dx.doi.org/10.1016/j. corsci.2010.09.027.

30. Ben Rhouma A, Amadou T, Sidhom H, Braham C. Correlation between microstructure and intergranular corrosion behavior of low delta-ferrite content AISI $316 \mathrm{~L}$ aged in the range 550 e $700{ }^{\circ} \mathrm{C}$. J Alloys Compd. 2017;708:871-86. http://dx.doi. org/10.1016/j.jallcom.2017.02.273.

31. American Society for Testing and Materials. ASTM A262-13: standard practices for detecting susceptibility to intergranular attack in austenitic stainless steels. Philadelphia: ASTM International; 2013.

32. Garcia C, Martin F, de Tiedra P, Blanco Y, Lopez M. Pitting corrosion of welded joints of austenitic stainless steels studied by using an electrochemical minicell. Corros Sci. 2008;50(4):118494. http://dx.doi.org/10.1016/j.corsci.2007.11.028.

33. Lee DJ, Byun JC, Sung JH, Lee HW. The dependence of crack properties on the $\mathrm{Cr} / \mathrm{Ni}$ equivalent ratio in AISI $304 \mathrm{~L}$ austenitic stainless steel weld metals. Mater Sci Eng A. 2009;513-514:1549. http://dx.doi.org/10.1016/j.msea.2009.01.049.

34. Kim YH, Lee DJ, Byun JC, Jung KH, Kim JI, Lee HJ, et al. The effect of sigma phases formation depending on $\mathrm{Cr} / \mathrm{Ni}$ equivalent ratio in AISI 316L weldments. Mater Des. 2011;32(1):330-6. http://dx.doi.org/10.1016/j.matdes.2010.06.044.

35. Bansod AV, Patil AP, Moon AP, Shukla S. Microstructural and electrochemical evaluation of fusion welded low-nickel and $304 \mathrm{SS}$ at different heat input. J Mater Eng Perform. 2017;26(12):5847-63. http://dx.doi.org/10.1007/s11665-0173054-3.

36. Tavares SSM, Feijó GF, Farneze HN, Sandim MJR, Souza IR Fo. Influence of microstructure on the corrosion resistance of AISI 317L. Mater Res. 2017;20(Suppl. 2):108-14. http://dx.doi. org/10.1590/1980-5373-mr-2016-1107. 